\title{
A COVID-19 EM CHARGES: UMA ANÁLISE BASEADA EM FRAMES
}

COVID-19 IN CARTOONS:

A FRAME-BASED ANALYSIS

\section{Paulo Henrique Duque \\ Universidade Federal do Rio Grande do Norte}

Resumo: O presente trabalho analisa e discute os sentidos da COVID-19 em charges publicadas entre os meses de janeiro e julho de 2020, período crítico em que a doença se instalou e se espalhou pelo Brasil. Tal análise é pautada na Semântica de Frames, vertente da Linguística Cognitiva segundo a qual sistemas estruturados de conhecimento, denominados frames, são acessados por elementos presentes no texto. Para a elaboração do corpus, recorremos à técnica de saturação teórica, ferramenta conceptual empregada em investigações qualitativas para estabelecer o tamanho final de uma amostra, com a indicação de um limite para a captação de novos dados. Quanto à investigação, procedemos ao levantamento de pistas verbais e não-verbais salientes nos textos captados, à identificação de possíveis redes conceptuais (frames) modeladas pelas pistas, à representação gráfica dos frames e, por fim, à análise e discussão dos 6 frames identificados: GOVERNO; NEGACIONISMO; PROTEÇÃO; CONTAMINAÇÃO; AGLOMERAÇÃO e ECONOMIA.

Palavras-Chave: Linguagem e Cognição; Frame; COVID-19; Charge.

${ }^{1}$ Endereço eletrônico: duqueph@gmail.com 
Abstract: This paper analyzes and discusses the meanings of COVID-19 in cartoons published between January and July 2020, a critical period in which the disease settled and spread throughout Brazil. This analysis is based on Frame Semantics, aspect of Cognitive Linguistics according to which structured systems of knowledge, called frames, are accessed by elements present in the text. For the elaboration of the corpus, we used the technique of theoretical saturation, a conceptual tool used in qualitative investigations to establish the final size of a sample, with the indication of a limit for the capture of new data. Regarding the investigation, we proceeded to the survey of verbal and non-verbal clues protruding in the texts captured, the identification of possible conceptual networks (frames) modeled by the clues, the graphic representation of the frames and, finally, the analysis and discussion of the 6 frames identified: GOVERNMENT; DENIALISM; PROTECTION; CONTAMINATION; AGGLOMERATION and ECONOMY.

Keywords: Language and Cognition, Frame, COVID-19, cartoon.

\section{INTRODUÇÃO}

Desde dezembro de 2019, passamos a coexistir com uma doença altamente contagiosa: a COVID-19 (COrona VIrus Disease ${ }^{2}$ - 2019), transmitida por um novo coronavírus, o SARS-CoV-2. Raramente, esse tipo de vírus chega a infectar pessoas. No entanto, naquele mês, foram registrados os primeiros casos de COVID-19. Em 5 de janeiro de 2020, houve o primeiro comunicado da Organização Mundial da Saúde (OMS) acerca de 44 casos de "pneumonia de causa desconhecida" relacionada ao Mercado de Wuhan/China. No dia 30 de janeiro, a OMS declarou emergência internacional, e, no dia 11 de março, pandemia de COVID-19.

Entre janeiro e março de 2020, o aumento exponencial de infectados pela doença despertou a atenção da imprensa do mundo inteiro e, desde então, o assunto se tornou destaque nos meios de comunicação. A despeito da gravidade da situação, o assunto passou a ser foco até mesmo de categorias discursivas normalmente caracterizadas pelo humor, como é o caso da charge. Comum em jornais e revistas, impressos ou online, a charge ${ }^{3}$ retrata fatos sociais ou políticos relevantes, de forma bem-humorada. Para isso, faz uso do exagero, em especial,

\footnotetext{
2 Doença causada pelo Coronavírus.

${ }^{3}$ De acordo com Parnaíba e Gobbi (2014), o termo "charge" se origina do francês charger, com o significado de carga, no sentido de carregar, exagerar ou atacar violentamente uma carga de cavalaria.
} 
por meio da caricatura, em que o chargista enfatiza pontos salientes e cria distorções da realidade.

Mas como abordar a COVID-19 de forma bem-humorada? A fim de verificarmos alguns conceitos recorrentemente relacionados à doença, na fase inicial da pandemia no Brasil, identificamos estruturas conceptuais, ou frames, evocados por elementos verbais e não-verbais de charges publicadas nos meses de janeiro a junho de 2020, em jornais e revistas online. Para a elaboração do corpus, recorremos à técnica de saturação teórica, ferramenta conceptual empregada em investigações qualitativas para estabelecer o tamanho final de uma amostra, com a indicação de um limite para a captação de novos dados.

\section{FRAMES}

Para elucidarmos as pistas verbais e/ou não-verbais de uma charge, precisamos identificar o(s) frame(s) evocado(s) por essas pistas na mente de um potencial leitor. De acordo com Fillmore (1982, p. 111), um frame é

qualquer sistema de conceitos relacionados de tal maneira que, para compreender qualquer um desses conceitos, você precisa compreender a estrutura inteira em que tal conceito se encaixa; quando uma das coisas de tal estrutura é introduzida em um texto, ou em uma conversação, todas as outras automaticamente se tornam disponíveis ${ }^{4}$.

Em situações discursivas, portanto, a escolha lexical pressupõe um pano de fundo cognitivo constituído pelos conhecimentos e experiências pré-existentes na sociedade em que estamos inseridos. Para compreendermos as relações entre

4 " [...] any system of concepts related in such a way that to understand any one of them you have to understand the whole structure in which it fits; when one of the things in such a structure is introduced into a text, or into a conversation, all of the others are automatically made available" (FILLMORE, 1982, p. 111). 
"comprar" e "vender", por exemplo, precisamos acessar o frame do evento TRANSAÇÃO COMERCIAL ${ }^{5}$.

Embora Fillmore (1982, p. 111) tenha iniciado sua pesquisa sobre a semântica de frames com a intenção de encontrar um "jeito particular de olhar para o significado das palavras, bem como uma maneira de caracterizar os princípios de criação de novas palavras e frases $6^{\prime \prime}$, estendemos o escopo dessa abordagem a fim de incluirmos os componentes não-verbais da charge.

De acordo com Duque (2017), cada frame apresenta dimensões esquemáticas, conceptuais básicas, socioculturais, interacionais, de evento, de roteiro e de domínios específicos. Cada componente do frame é um conceito que se encontra em estado de base (segundo GABORA; ROSCH; AERTS, 2008, groundstate), isto é, um estado teórico que precisa ser colapsado ${ }^{7}$ num contexto mais amplo. Portanto, um conceito se torna mais preciso quando se conecta a outro conceito ou quando integra um frame de evento, de roteiro ou de interação. Observemos os exemplos (1), (2), (3) e (4).

(1) ilha da cozinha

(2) o animal latiu várias vezes

(3) perdi a entrada da noiva

(4) a recepcionista me informou o número do quarto

Os termos sublinhados têm seus sentidos refinados respectivamente, em (1), por outro conceito básico, COZINHA; em (2), pelo frame-evento LATIR; em (3), pelo frame-roteiro CASAMENTO; e (4), pelo frame-interacional PEDIDO DE

\footnotetext{
5 A fim de se estabelecermos uma uniformidade notacional, ao tratarmos de formas linguísticas, adotamos aspas simples (o verbo 'comprar'); ao tratarmos de enunciados, adotamos aspas duplas ("comprar"); ao tratarmos de estruturas conceptuais, adotamos fontes em versalete (COMPRADOR).

6 " [...] a particular way of looking at word meanings, as well as a way of characterizing principles for creating new words and phrases [...] (FILLMORE, 1982, p. 111).

${ }_{7}$ De acordo com Gabora, Rosch e Aerts (2008), quando o conceito (frame) é especificado por um contexto (frame interacional e frame evento), ocorre um colapso. Em outras palavras, passamos de uma condição de imprecisão para uma condição de precisão semântica.
} 
INFORMAÇÃO. Há conceitos de base, no entanto, que devido à recorrência com que são associados a determinados frames tornam-se auto-estados (Segundo GABORA; ROSCH; AERTS, 2008, eigenstate) desses frames. Por exemplo, o conceito de base QUADRO DE GIZ é recorrente em situações de sala de aula. Logo, por si só, a expressão é capaz de evocar o frame SALA DE AULA.

O frame de evento TRANSAÇÃO COMERCIAL, por sua vez, apresenta um estado inicial (o comprador tem o dinheiro e quer a mercadoria e o vendedor tem a mercadoria e quer o dinheiro.), uma ação (o comprador dá o dinheiro ao vendedor ou o vendedor dá a mercadoria ao comprador), e um estado final (o comprador tem a mercadoria e o vendedor tem o dinheiro). Essa composição sequencial do frame de evento se fundamenta no estudo de Nance (1981), para quem, evento é uma ação que, localizada no tempo, leva a uma mudança de estado. Dada a transição de estados presente em um frame de evento, podemos fazer inferências sobre estados prévios e estados posteriores. Por exemplo,

(5) Pedro comprou o apartamento de Soraya

Com base em (5), podemos inferir que Pedro passou a ser o proprietário do apartamento e que, agora, Soraya tem mais dinheiro que antes. A ideia é que as fronteiras dos significados evocados por verbos como 'comprar' e 'vender' vão além do escopo da ação em si. O intervalo ampliado de significação, nesse caso, contempla a revelação de estados prévios e a predição de estados posteriores.

Assim como os eventos centrados em processos físicos, eventos voltados para situações de interação também podem ser representados por frames. Segundo Fillmore (1982), frames interacionais guiam nossa participação em situações de interação social ${ }^{8}$. Graças a essas estruturas conceptuais, sabemos como reconhecer e como nos posicionar dentro de um determinado jogo de linguagem e como categorizar discursos disseminados em situações específicas.

\footnotetext{
${ }^{8}$ Para Duque (2017), situações de interação social correspondem a jogos de linguagem, isto é, atividades em que os envolvidos buscam compartilhar atenção para um objeto, um evento, um conceito etc.
} 
O frame interacional PEDIDO DE INFORMAÇÃO, por exemplo, nos orienta sobre como pedir/dar informações e sobre que categorias discursivas precisamos conhecer para executar eficientemente um pedido de informação (por exemplo, MAPAS, PERGUNTAS-RESPOSTAS, GUIA DE RUAS etc.).

Quanto à representação gráfica do frame, para Souza e Duque (2018), tal estrutura conceptual pode ser representada por meio de grafos, isto é, por uma rede de nós e arestas, em que os nós correspondem aos conceitos e as arestas aos esquemas ${ }^{9}$ que conectam esses conceitos. Vejamos uma representação em grafo do frame de evento TRANSAÇÃO COMERCIAL (figura 1).

Figura 1 - grafo do frame de evento TRANSAÇÃO COMERCIAL

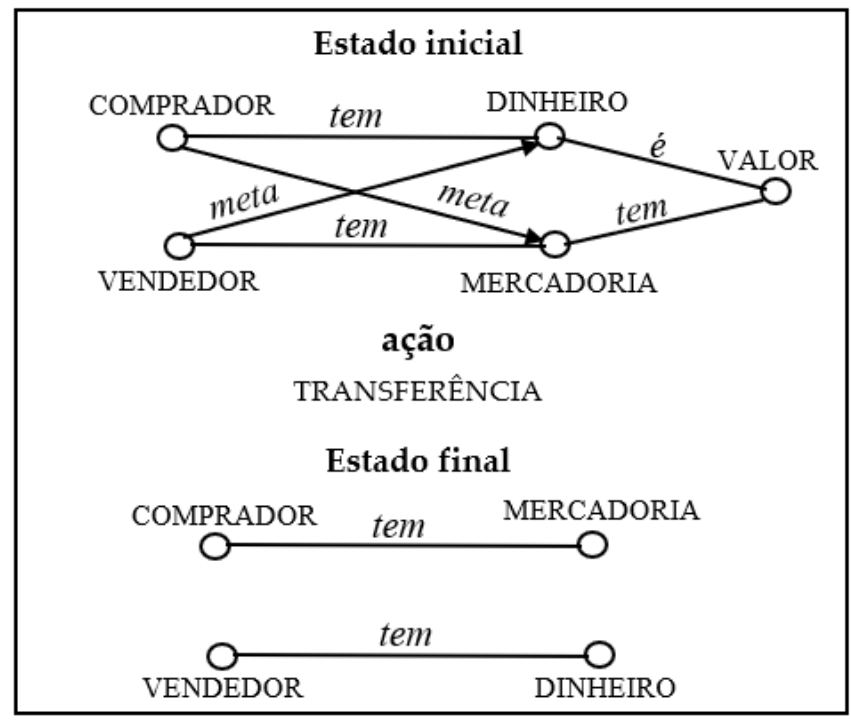

Fonte: autor

No grafo da figura 1, o frame de evento TRANSAÇão COMERCIAL é representado em três partes: estado inicial, ação e estado final. Nesse caso, a seleção lexical pode enquadrar, ou a transferência que envolve deslocamento de dinheiro, do comprador para o vendedor (por exemplo, "comprar"), ou a transferência que envolve deslocamento de mercadoria, do vendedor para o comprador (por exemplo, "vender").

9 Esquemas, aqui, são concebidos como estruturas conceptuais fundamentadas em movimentos corporais recorrentes no espaço, interações perceptuais e formas de manipular objetos (HAMPE, 2005). 
Um frame, portanto, constitui uma estrutura conceptual evocada (e reforçada) por um conjunto de pistas verbais e não-verbais e se relaciona com domínios da experiência humana, na forma de eventos físicos ou interacionais, tais como AMASSAR, TRANSAÇÃO COMERCIAL e AULA, e de elementos que integram esses eventos, tais como LATA, DINHEIRO e CADERNO, respectivamente.

\section{ENQUADRAMENTO CONCEPTUAL}

De acordo com Lakoff (2004), o enquadramento (ou framing) é um processo discursivo de elaboração de frames. Como vimos na seção anterior, um frame é um sistema constituído de conceitos esquematicamente relacionados de modo que, para entendermos um único conceito, precisamos dar conta de todo o sistema conceptual. Segundo o autor, frames parecem influenciar diretamente nossas visões de mundo e, portanto, são responsáveis pelos nossos comportamentos políticos e sociais (LAKOFF, 2004). Defendemos, aqui, que a elaboração de um frame se inicia a partir do contato com os sinais verbais e/ou não-verbais do texto.

Nesse sentido, quando detectamos os sinais do texto, o framing nos oferece um direcionamento semântico e perceptual que enfatiza determinadas visões de mundo em detrimento de outras. Apesar de ocorrer de forma inconsciente, esse mecanismo discursivo-cognitivo pode ser tecido de modo que determinados frames sejam evocados e integrados entre si na produção de discursos persuasivos como os de textos do domínio da política e do humor. A charge, em especial, se enquadra em ambos os domínios.

Como já assinalado anteriormente, charges são textos que,

[...] por meio do humor, do sarcasmo, da ironia, buscam denunciar de maneira 'caricaturada' revelações e flagras acerca de comportamentos, atitudes e visões do mundo e das realizações naturais e culturais, à luz de percepções consideradas inapropriadas, incorretas, fora do padrão ou daquilo que se espera da humanidade. (ALVES SILVA, 2015, p. 67) 
Diferente de outras categorias de natureza predominantemente não-verbal, a charge transmite informações que envolvem fatos e, ao mesmo tempo, tece críticas. Em linhas gerais, a charge consiste na representação gráfica de um assunto relevante do momento, orientada pela visão do chargista e do jornal.

Nas charges, normalmente, há o fornecimento de pistas gráficas de caracterização de cenários, personagens etc., que contribuem sobremaneira para a evocação de frames. No caso da COVID-19, quanto à representação gráfica do coronavírus, cumpre salientar que o vírus possui espinhos em forma de coroa quando visto em um microscópio (Figura 2).

Figura 2 - Micrografia eletrônica de transmissão de um Coronavírus

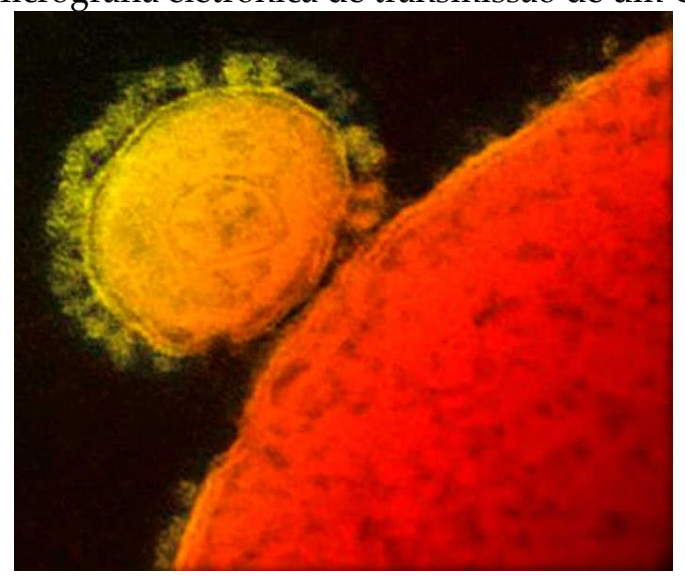

Fonte: NIAID/ RML10

Com base nessa informação visual, o coronavírus é representado graficamente como uma esfera rodeada de espinhos, como na Figura 3.

Figura 3- Representação gráfica do Coronavírus responsável pela COVID-19

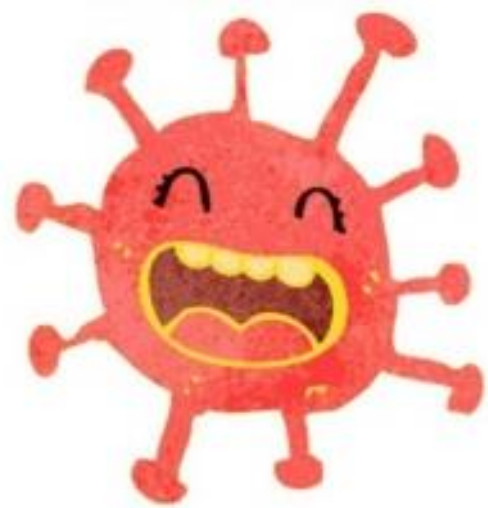

Fonte: Molina (2020)

${ }^{10}$ National Institute of Allergy and Infectious Diseases/ Rocky Mountain Laboratories (em Hamilton, Montana, EUA). 
O vírus só pode ser visto com o auxílio de microscópios, mas a sua representação gráfica, Figura 3, se tornou bastante popular, graças às campanhas de prevenção à COVID-19. Veremos que o formato e as características físicas do vírus determinam não só a forma como ele é representado graficamente nas charges, mas também delimitam os tipos de objetos com os quais o coronavírus é comparado: normalmente, com objetos esféricos que se deslocam no ar.

\section{A CATEGORIA DISCURSIVA CHARGE}

$\mathrm{O}$ fato de apresentarmos aqui a charge como categoria discursiva não significa que seja facilmente identificável, que seja facilmente formalizável e que não sofra mutações, mas sim que suas características (traço do desenho, uso de cores, tipo de caricatura etc.) variem em graus de relevância em função dos protótipos de cada cultura, cada jornal e cada artista.

Os protótipos de uma categoria discursiva emergem de mudanças que ocorrem nas sociedades e em seus discursos materializados em textos. Dessa forma, à medida que as práticas sociais se transformam por meio dos discursos de seus usuários, as categorias discursivas tendem a se transformar.

A representação exagerada, muitas vezes até agressiva (SOUZA; DRIGO, 2006), é característica mais saliente de uma charge e serve de instrumento para se produzir o humor. A partir de uma distorção proposital por parte do chargista, somos levados a enquadramentos, muitas vezes, até então desconhecidos. Ao equipararmos o coronavírus a uma pessoa disfarçada tentando se infiltrar numa aglomeração, por exemplo, somos levados a repensar os acontecimentos na perspectiva do vírus, o que pode ser saudável em termos de reflexão sobre sua ameaça invisível.

Segundo Romualdo (2000, p. 27), ao utilizar-se do ridículo como recurso, caricaturas não apenas fazem rir, mas também fazem refletir. Achamos graça do que é saliente, mas só somos capazes de compreender a caricatura se conhecemos 
a pessoa a quem a ilustração se refere. Daí a importância dos frames que possuímos antes mesmo da leitura. Cumpre salientar que, por abordar assuntos em destaque na mídia, a charge tem prazo de validade. Depois que a notícia "esfria", a charge pode perder a graça, não haver mais humor e se tornar apenas um registro, visto que, segundo o autor,

[...] por causa das transformações constantes que vivem os homens e as sociedades, o contexto social se modifica e, por isso, quando revemos velhas caricaturas ou charges não compreendemos muitas vezes a intenção e o humor desses textos. (ROMUALDO, 2000, p. 42)

Sobre a temporalidade, Souza e Drigo (2006) afirmam que a charge se revela como um traço da história, na medida em que capta o processo no devir. É uma categoria discursiva que sintetiza um fato registrando a imagem do seu tempo, levando às futuras gerações o modo de pensar de uma época, mas que o tempo altera. No caso da COVID-19, por exemplo, de janeiro a julho, diferentes situações ocorreram que alteraram a forma de encararmos os fatos.

A charge quase sempre se vincula a outras categorias discursivas do discurso jornalístico. Quanto a esse aspecto, Romualdo (2000, p. 2) afirma que "o fato de encontrarmos, em textos veiculados pelo próprio jornal, informações diversas que nos permitam interpretar a charge, mostra que esta mantém relações intertextuais com os outros textos jornalísticos."

Devido a essa vinculação entre textos de categorias diferentes, segundo Almeida (2020), ao ser transportado para um corpus, o texto deixa de ser uma unidade de uma determinada categoria discursiva, e muda sua natureza, passando a constituir uma nova categoria discursiva, o corpus, que, por sua vez, é "parte de outros novos gêneros: artigos, dissertações, teses" (ALMEIDA, 2020, p. 159). Conforme salienta a autora,

um poema não nasce corpus de pesquisa, mas transforma-se em objeto ou ferramenta de pesquisa, pelo deslocamento de cultura literária em face da cultura científica (ALMEIDA, 2020, p. 160). 
Ocorre o mesmo com a charge. Não podemos perder de vista, portanto, que estamos lidando com "textos coletados, selecionados, organizados, tratados e disponibilizados, para uso em pesquisa" (ALMEIDA, 2020, p. 160).

Cumpre ressaltar ainda que, por atuar em uma empresa de comunicação, muitas vezes, o chargista reflete os posicionamentos do editorial do jornal ou revista em que a charge é publicada. Nesses casos, a leitura do texto a que a charge se vincula pode fornecer pistas importantes de interpretação.

\section{METODOLOGIA}

O objeto de investigação corresponde a conceptualizações da COVID-19 em charges publicadas entre janeiro e julho de 2020, ocasião em que lançamos mão da técnica da saturação teórica como estratégia de elaboração dos dados.

Para o desenvolvimento da pesquisa, um corpus foi previamente elaborado e delimitado, adotando-se uma adaptação do procedimento metodológico da saturação teórica (GLASER; STRAUSS, 1967) de amostragem. Para a elaboração do corpus de charges da pesquisa em questão, com o auxílio da ferramenta de busca Google Imagens, digitei o termo "pandemia OR COVID19 OR coronavírus AND charge" o que me forneceu 613 imagens. Dessas imagens, foram eliminados cartuns, tirinhas, fotografias e quadrinhos, o que resultou em 515 charges, sobre as quais apliquei a saturação teórica.

A saturação teórica normalmente é utilizada na coleta de dados por meio de entrevistas, técnicas de observação, grupo focal e aplicação de questionários, nas áreas de Administração e Saúde. De acordo com Falqueto e Farias (2016), esse método constitui um dispositivo conceptual empregado em investigações qualitativas. Segundo os autores, é uma ferramenta usada para estabelecermos a dimensão final de uma amostra por meio da interrupção da inserção de novos dados no corpus. 
Nessa técnica, o número de textos é operacionalmente definido como a suspensão de inclusão de novos textos quando os dados obtidos passam a apresentar, na avaliação do pesquisador, certa redundância ou repetição, não sendo considerado produtivo persistir na coleta de dados. Embora o Google tenha nos fornecido 515 charges, foram necessários 60 textos ${ }^{11}$ para chegarmos ao ponto de saturação teórica.

Quanto à utilização da técnica na delimitação de corpus constituído por textos, Santana (2019) o adota para a delimitação de seu corpus constituído de cartas de amor. A autora recorreu ao processo de saturação, devido a dificuldades encontradas para a composição dos corpora de sua tese, em termos de determinação do tamanho final da amostra. Sendo assim, "a amostra foi considerada representativa, quando as ocorrências não acrescentavam novas conceptualizações para o AMOR" (SANTANA, 2019, p. 83).

A forma de constituição de um corpus que seja representativo do contexto sob investigação é um aspecto relevante de validação de pesquisas científicas, tendo em vista que os dados analisados emergem fundamentalmente dos textos que compõem a amostra. Nesse sentido, segundo Falqueto e Farias (2016), para que se garanta o rigor científico, a adoção da saturação teórica na delimitação do corpus precisa envolver uma combinação de critérios: os limites empíricos dos dados, a integração desses dados com uma teoria, e a sensibilidade teórica de quem os analisa. Desse modo, a saturação teórica tem legitimidade lógica, mas, segundo os autores (FALQUETO; FARIAS, 2016, p. 561), "se aplica somente a casos específicos no âmbito das pesquisas de caráter qualitativo, além de depender da conceptualização precisa das categorias teóricas analisadas e das propriedades investigadas".

\footnotetext{
${ }^{11}$ Devido a questões de direitos autorais do uso de textos e imagens da internet, as charges analisadas não foram anexadas ao artigo, mas há os links que conduzem o leitor aos sites e blogs em que foram originalmente publicadas.
} 
No emprego da técnica, a construção e a análise de dados precisam ocorrer concomitantemente, para que se possam identificar os elementos que surgem e os elementos que estão sendo replicados. Segundo Falqueto e Farias (2016), chega-se à saturação teórica quando o pesquisador conclui que a interação entre as atividades de coleta de novos elementos e a percepção do investigador não mais fornecem elementos para demarcar ou aprofundar a teorização. Seguindo a orientação dos autores, adotamos as 5 etapas de constatação da saturação teórica da amostra de charges:

Primeiro, definimos os frames subjacentes às pistas verbais e não-verbais detectadas nas charges. No caso as categorias foram sendo definidas ao longo do exame de cada charge fornecida pelo banco de imagens do Google.

Segundo, definimos o roteiro de pesquisa. Com as categorias definidas, o passo seguinte requereu a construção de um roteiro. Esse esquema parece facilitar o processo para encontrarmos o ponto de saturação, uma vez que coube ao pesquisador identificar os elementos em cada charge e verificar as repetições. A seguir, no quadro 1, apresentamos o roteiro construído para o caso relatado.

\begin{tabular}{|l|}
\multicolumn{1}{c|}{ Quadro 1 - Roteiro de pistas } \\
\hline \multicolumn{1}{|c|}{ Roteiro de pistas } \\
\hline Como o Coronavírus é representado graficamente? \\
Que personagens estão na charge? \\
Qual o cenário em que ocorre o evento da charge? \\
Qual é o evento da charge?
\end{tabular}

Fonte: autor

Terceiro, levantamos informações novas versus informações confirmadas em cada coleta. Por meio de análise, identificamos as informações relevantes e as categorizamos. Assim, os dados brutos foram levados a níveis mais amplos que nos permitiram caracterizar o conteúdo relevante das charges de forma mais sistemática. Ao explorarmos individualmente cada charge, antes de partir para a seguinte, informações novas foram diferenciadas das que já haviam sido citadas anteriormente em outras charges. A partir da $41^{\underline{a}}$ charge, não identificamos novos frames que fossem relevantes para a pesquisa. Mesmo assim, como recomenda Thiry-Cherques (2009), analisamos outras charges a fim de confirmar o ponto de 
saturação. Considerando os dois conjuntos de charges analisadas, foram encontrados 6 frames recorrentes: 1 - GOVERNO; 2 - NEGACIONISMO; 3 - PROTEÇÃO; 4 - CONTAMINAÇÃO; 5 - AGLOMERAÇÃO e 6 - ECONOMIA.

Quadro 2 - Análise da charge 1 com identificação das informações novas

\begin{tabular}{|ll|}
\hline \multicolumn{1}{|c|}{ Charge 1 } \\
\hline \multicolumn{2}{|c|}{ CONTAMINAÇÃO } \\
\hline 1. & Coronavírus é uma pessoa (viajante) \\
\hline 2. & Bagagem \\
\hline 3. & Viajante/ grupo de pessoas \\
\hline 4. & Aeroporto \\
\hline 5. & Caminhando/ parado \\
\hline
\end{tabular}

Fonte: autor

Quadro 3 - Análise da charge 3 com a confirmação de informações e a inclusão de novas informações

\begin{tabular}{|clc|}
\hline \multicolumn{2}{|c|}{ Charge 3 } \\
\hline & GOVERNO \\
\hline & & INCLUIU \\
\hline 6. & Sem objetos relevantes \\
\hline 7. & Médico \\
\hline 8. & Posto de saúde & \\
\hline & & \\
\hline 1. & Coronavírus não aparece & \\
\hline 2. & Pessoa comum & \\
\hline 3. & Repouso & \\
\hline
\end{tabular}

Fonte: autor

Quarto, registramos em uma tabela o que foi encontrado de novo em cada coleta, a fim de facilitar a visualização dos elementos analíticos que foram levantados nas charges. A título de exemplificação, apresentamos trechos da Tabela (Tabela 1). Nas linhas, foram atribuídos o valor de 1, para informar que havia, pelo menos, uma nova informação e -, para indicar que não foi encontrada nenhuma nova informação na respectiva charge.

Tabela 1 - Saturação teórica das charges coletadas

\begin{tabular}{|c|c|c|c|c|c|c|c|c|c|c|c|c|c|c|c|c|c|c|c|c|}
\cline { 2 - 2 } \multicolumn{1}{c|}{} & \multicolumn{10}{c|}{ Charges } \\
\hline Categorias & 1 & 2 & 3 & 26 & 27 & 28 & 29 & 30 & 31 & 32 & 33 & 34 & 35 & 36 & 37 & 38 & 39 & 40 & 41 & 42 \\
\hline GOVERNO & - & 1 & 1 & 1 & - & - & 1 & 1 & - & - & - & - & - & 1 & - & - & 1 & - & - & - \\
\hline PROTEÇÃO & - & - & - & - & 1 & - & - & - & - & - & - & - & - & - & - & - & - & - & - & - \\
\hline NEGACIONISMO & - & - & - & - & - & - & 1 & - & 1 & 1 & 1 & - & - & 1 & 1 & & - & - & 1 & - \\
\hline ECONOMIA & - & - & - & - & - & - & - & - & - & -- & - & 1 & - & - & - & 1 & - & 1 & - & - \\
\hline CONTAMINAÇÃO & 1 & - & - & - & - & 1 & - & - & - & - & - & - & 1 & - & - & - & - & - & - & - \\
\hline AGLOMERAÇÃO & - & - & - & 1 & - & - & - & - & - & - & - & - & - & - & - & - & - & - & - & - \\
\hline
\end{tabular}

Fonte: autor

Quinto, confirmamos a saturação de cada frame. Ao observarmos a tabela 1, verificamos que, para o frame AGLOMERAÇÃO, o ponto de saturação ocorreu na 
charge 26. Entretanto analisamos mais charges porque outros frames ainda não haviam atingido a saturação. A saturação teórica geral se deu na charge de número 41, porque, a partir desse ponto, nenhuma nova informação foi considerada relevante para a teorização. Após essa constatação, mesmo assim, novas charges foram analisadas para a necessária confirmação. No caso de entrevistas, conforme Falqueto e Farias (2016), recomenda-se que sejam feitas duas entrevistas adicionais, depois de encontrado o ponto de saturação. No estudo relatado, no entanto, devido à complexidade da categoria discursiva em questão, optamos por analisar mais 19 charges, a fim de se obter uma margem de segurança em relação à saturação.

\section{ANÁLISE}

A análise se divide em dois enquadramentos: a linha histórica das charges, dividida por meses (de janeiro a junho), e os frames recorrentemente evocados (GOVERNO; NEGACIONISMO; $\quad$ PROTEÇÃO; CONTAMINAÇÃO; $\quad$ AGLOMERAÇÃO; ECONOMIA).

\subsection{A linha histórica das charges}

A COVID-19 vem sendo enquadrada de diferentes maneiras ao longo de 2020: em janeiro e fevereiro, o foco recaiu na entrada do coronavírus no Brasil e seu espalhamento por estados e municípios.

As charges normalmente enquadram o coronavírus como sendo um turista chegando ao Brasil ${ }^{12}$. Nessas charges, o aeroporto é o cenário mais comum e o coronavírus é representado como turista. Em outras charges, o coronavírus é representado como pessoa adentrando cidades e casas e sendo combatido com spray de álcool em gel.

12 Disponível em: https://www.otempo.com.br/super-noticia/charges/charge-o-tempo-28-012020-1.2289921. Acesso em: 31 ago. 2020. 
Logo após o carnaval, as charges passaram a representar a COVID-19 se somando às doenças transmitidas pelo mosquito Aedes Aegypti ${ }^{13}$. Há muitas charges abordando as doenças COVID-19, Dengue Chikungunya e Zica em conjunto, normalmente retratando o coronavírus como sendo expulso do Brasil por mosquitos transmissores dessas doenças. Em outras charges, o mosquito Aedes Aegypti reclama da "perda do posto" de transmissor popular para o coronavírus.

Em março, a OMS declarou pandemia e, logo em seguida, foi implantada a quarentena e o fechamento de escolas, de universidades e do comércio pelas autoridades. As charges desse período reforçam a importância de se permanecer em casa, de se evitarem aglomerações e de se proteger contra a COVID-19. Muitas charges retratam os percalços do trabalho remoto, em home office.

Nesse período também houve o aumento do negacionismo, impulsionado, principalmente, pelas declarações do presidente da república. As charges passaram a retratar o descaso, normalmente, caracterizando declarações controversas do presidente sobre a COVID-19. Outras vezes, as charges representam o presidente da república, normalmente vendado com a própria máscara ${ }^{14}$, conduzindo o país para o abismo ou tomando decisões importantes para a nação ${ }^{15}$.

Paralelamente a isso, os casos de COVID-19 aumentavam exponencialmente e o número de mortos passou a ser divulgado com mais frequência. Nesse contexto, muitas charges abordam o noticiário sobre aumento do número de casos. Crânios, esqueletos ${ }^{16}$ e cruzes passam a ser usados para

13 Disponível em: https://www.portalodia.com/blogs/jotaa/confira-a-charge-de-jota-apublicada-na-edicao-desta-segunda-no-jornal-o-dia-373993.html. Acesso em: 31 ago. 2020.

${ }^{14}$ Durante coletiva de imprensa com seus ministros, em 18/3/2020, o presidente da república demonstrou que não sabia usar corretamente a máscara de proteção facial, para evitar o contágio por coronavírus, e acabou se tornando meme das redes sociais.

15 Disponível em: https://latuffcartoons.wordpress.com/2020/05/04/bolsonaro-e-ocoronavirus-em-charges/img_20200318_194123656-01/. Acesso em: 31 ago. 2020.

16 Disponível em: https://profscontraoesp.org/2020/03/23/resposta-ao-COVID-19-e-ead-nauniversidade. Acesso em: 31 ago. 2020. 
representar as mortes, bem como passa a ser recorrente o uso do ceifador como metáfora de personificação da morte.

Outro assunto que ganha relevância nas charges são os constantes desencontros entre a fala do ministro da saúde e a do presidente da república, que insiste em atacar o isolamento social e desconsidera a gravidade da COVID19, chamando-a de "gripezinha" ${ }^{17}$.

Em abril, torna-se evidente que, enquanto alguns podem e/ou têm condições de cumprir o isolamento social, há pessoas completamente desprotegidas e negligenciadas pelo poder público, e as charges abordam o tema ${ }^{18}$.

Outro tema recorrente do mês de abril é o desemprego causado pela crise e intensificado pelo fechamento do comércio e de empresas ${ }^{19}$. O uso da cloroquina $^{20}$, recomendada pelo presidente da república, como forma de tratamento precoce da COVID-19, também é bastante mencionada nas charges de abril.

Em maio e junho, a preocupação recai sobre o retorno das aglomerações com a realização de festas clandestinas ou com a reabertura do comércio em algumas cidades, além do aumento do número de casos e a tentativa de ocultação ${ }^{21}$ do número real de mortos pelo governo federal.

Assim, identificamos os principais frames evocados para enquadrar a COVID-19 em diferentes períodos da pandemia. Cumpre destacar que as pistas de algumas charges se circunscrevem a acontecimentos bem específicos, como a

17 Disponível em: https://www.agazeta.com.br/charge/charge-do-amarildo-bolsonaro-e-ocombate-ao-coronavirus-0320. Acesso em: 31 ago. 2020.

${ }^{18}$ Disponível em: https://blogdoaftm.com.br/charge-pessoas-em-situacao-de-rua/. Acesso em: 31 ago. 2020.

19 Disponível em: https://www.midiamax.com.br/politica/charge/2020/charge-a-cruz-dotrabalhador. Acesso em: 31 ago. 2020.

20 Disponível em: https://gauchazh.clicrbs.com.br/opiniao/iotti/noticia/2020/04/iotti-doutorck8teux5s01lz01ntvfg77e77.html. Acesso em: 31 ago. 2020.

${ }^{21}$ Disponível em: https://www.folhadedourados.com.br/multimidia/charges/charge-brasilesconde-dados-sobre-mortos-por-COVID-19. Acesso em: 31 ago. 2020. 
ocultação dos dados sobre a COVID-1922, pelo Ministério da Saúde, no dia 5 de junho de 2020.

\subsection{Os frames evocados}

Como já informado, agrupamos os seis frames evocados recorrentemente a partir das charges analisadas. A seguir essas charges são apresentadas da mais recorrente a menos recorrente, no período de janeiro a junho de 2020.

1- GOVERNO

A charge "ditadoido"23, publicada em 25/3/2020, mostra o presidente brincando com o coronavírus sobre sua mesa de trabalho. A imagem faz alusão à cena do filme "O Grande Didator", em que a personagem ditador Hinkel brinca com um globo terrestre ${ }^{24}$. A cena do filme caracteriza o descaso do ditador com o mundo e com as pessoas. Ele trata o mundo como se fosse um grande brinquedo à mercê de seu ego inflado. Na famosa cena, o chargista substitui o ditador, pelo presidente da república, e o globo terrestre, pelo coronavírus. Com a integração dos frames CENA DO FILME e GOVERNO, o presidente se diverte com o vírus, seu brinquedo, apesar da pandemia.

\section{2- NEGACIONISMO}

A charge "Olavo, o guru do presidente" 25 , publicada em 24/3/2020, retrata o presidente sendo hipnotizado pelo ideólogo Olavo de Carvalho. No balão, há a frase "COVID-19 é histeria". Outras charges sobre negacionismo, recorrentemente, apresentam o presidente e/ou seus seguidores negando as

22 Disponível em: https://www.folhadedourados.com.br/multimidia/charges/charge-brasilesconde-dados-sobre-mortos-por-COVID-19. Acesso em: 31 ago. 2020.

23 Disponível em: https://www.flavioluiz.net/charges?lightbox=dataItem-kderv5e0. Acesso em: 27 ago. 2020.

${ }^{24}$ A representação gráfica do coronavírus como bola é frequente no corpus: bola de boliche, bola de sinuca, bola de beisebol e bola de futebol.

25 Disponível em: https://www.folhadelondrina.com.br/charge/charge-240320202983622e.html. Acesso em: 27 ago. 2020. 
afirmações da imprensa nacional e internacional, das instituições de pesquisa e dos órgãos de saúde sobre a COVID-19 e seu poder de contágio.

\section{3- PROTEÇÃO}

A charge "Antes e depois da Covid" 26, publicada em 18/3/2020, apresenta um assaltante rendendo um transeunte, em dois momentos: antes da COVID-19, em que o criminoso exige a carteira e o celular, e depois da COVID-19, em que o criminoso exige a máscara e o álcool em Gel. O texto alude à elevação exagerada de preços, devido ao aumento substancial da procura pelos referidos produtos.

\section{4- CONTAMINAÇÃO}

A charge “Não ajude" 27 , publicada em 19/4/2020, mostra o ceifador exausto devido ao grande número de mortes até então provocadas pela COVID-19. Em abril, há um grande aumento do número de casos e a preocupação com a falta de leitos em hospitais para tratamento dos casos mais graves. Nesse período, passa a ser comum a conceptualização metafórica por personificação do ceifador nas charges.

\section{5- AGLOMERAÇÃO}

A charge "Charge do Dia"28, publicada em 20/6/2020, apresenta um elevador cheio de pessoas. Sobre o marcador de nível, aparece a frase "e a linha da COVID-19 no Brasil..." e o ascensorista grita "Sobe". A charge faz alusão ao aumento do contágio provocado por aglomerações. Em outras charges sobre aglomerações, há a conceptualização metafórica do coronavírus como uma pessoa tentando se infiltrar em festas ou como uma criatura ameaçadora. Muitas vezes, é o ceifador que visita tais aglomerações.

26 Disponível em: https://www.leiagora.com.br/noticia/77816/antes-e-depois-do-COVID-19. Acesso em: 27 ago. 2020.

27 Disponível em: https://www.midiamax.com.br/politica/charge/2020/charge-nao-ajude. Acesso em: 27 ago. 2020.

28 Disponível em: https://imirante.com/oestadoma/noticias/2020/06/20/charge-do-dia/. Acesso em: 27 ago. 2020. 


\section{6- ECONOMIA}

A charge "Os Brasinhas do Espaço" ${ }^{29}$, publicada em 25/3/2020, apresenta o Capitão Gancho e seu ajudante, Estática, da série infantil "Brasinhas do Espaço", e um caldeirão no fogo cheio de trabalhadores. Na cena, o capitão solicita que seu ajudante retire os trabalhadores do caldeirão, pois está "apanhando muito". Ocorre uma integração de frames em que CAPITÃO GANCHO se mescla com PRESIDENTE DA REPÚBLICA, apelidado de "capitão" por seus seguidores. Seu ajudante, ESTÁTICA, se mescla com MINISTRO DA ECONOMIA, apelidado de "Posto Ipiranga" (símbolo na camisa), pelo presidente. No caldeirão está escrito MP 927, medida provisória que dispõe medidas trabalhistas para enfrentamento do estado de calamidade pública, dentre elas, medidas controversas como a suspensão de contratos de trabalho por quatro meses. Pressionado, o governo revoga o artigo que previa a suspensão.

\section{CONSIDERAÇÕES FINAIS}

Neste artigo, discutimos e analisamos a construção do conceito de COVID19 em charges. Vimos que conceitos podem ser modelados por meio de frames e que elementos do texto evocam essas estruturas conceptuais. A ideia básica é que não podemos depreender o significado de uma única pista sem acessar toda uma rede de conhecimentos inter-relacionados. No caso das charges, pistas verbais e não-verbais, em conjunto, evocam e reforçam tais estruturas.

A categoria discursiva charge se caracteriza por apresentar uma representação exagerada da realidade, por utilizar-se do ridículo no tratamento de temas, pelo caráter efêmero do texto, por evocar a intertextualidade, por vincular diferentes textos de diferentes categorias do veículo de comunicação em que é publicada e pelo fato de o chargista, muitas vezes, refletir os

\footnotetext{
29 Disponível em: http://pioneiro.clicrbs.com.br/rs/geral/noticia/2020/03/iotti-confira-acharge-desta-quarta-feira-12294431.html. Acesso em: 27 ago. 2020.
} 
posicionamentos políticos do editorial do jornal ou da revista em que a charge é publicada.

Com base em dados coletados de janeiro a julho de 2020, a COVID-19 foi retratada em charges em termos do descaso do governo com a COVID-19; do negacionismo; das medidas de proteção contra a COVID-19; do aumento exponencial dos casos de COVID-19; das aglomerações; e da crise econômica em meio à pandemia. Para isso, os autores se valeram dos acontecimentos proeminentes em cada fase da pandemia: da entrada do coronavírus no país, sua disseminação por estados e municípios, às declarações polêmicas do presidente da república.

\section{REFERENNCIAS}

ALMEIDA, A. A. D. A tessitura do conhecimento: o corpus na construção de estudos semânticos sócio-histórico-cognitivos. In: SOUZA, R. B. de; SOUZA, D. de; ALMEIDA, I. S. de; SOUZA, D. de (Orgs.) Filologia em diálogo: descentramentos culturais e epistemológicos, Salvador: Memória \& arte, 2020, p. 148-184.

ALVES SILVA, C. Gênero Discursivo Charge: Do portal do professor ao ambiente virtual de aprendizagem. 2015. 198 f. Dissertação (Mestrado Profissional em Letras) Instituto de Letras e Linguística, Universidade Federal de Uberlândia, Uberlândia.

BRESSANIN, A. Gênero charge na sala de aula: o sabor do texto. In: $4^{o}$ Simpósio Internacional de Estudos de Gêneros Textuais, 2007. Disponível em: http://linguagem.unisul.br/paginas/ensino/pos/linguagem/eventos/cd/Port/8.pdf.

Acesso em: 1 set. 2020.

DUQUE, P. H. De perceptos a frames: Cognição Ecológica e Linguagem. Scripta, Belo Horizonte, v. 21, n. 41, p. 21-45, jan./jul. 2017.

DUQUE, P. H. Percepção, Linguagem e Construção de Sentidos: por uma abordagem ecológica da cognição. In: TENUTA, A. M.; COELHO, S. M. (Org.). Uma Abordagem Cognitiva da Linguagem: perspectivas teóricas e descritivas. Belo Horizonte: FALE/UFMG, 2018, p. 31-46.

FALQUETO, J.; FARIAS, J. Saturação teórica em pesquisas qualitativas: relato de uma experiência de aplicação em estudo na área de administração. In: Atas - Investigação Qualitativa em Ciências Sociais. Atas do $5^{\underline{o}}$ Congresso Ibero-americano em investigação qualitativa. v.3, p. 560-569, 2016. 
FILLMORE, C. J. Frame semantics. In: THE LINGUISTIC SOCIETY OF KOREA (Eds.). Linguistics in the Morning Calm. Seoul: Hanshin, 1982, p.111-37.

FILLMORE, C. J. Frame Semantics and the Nature of Language. Annals of the New York Academy of Sciences: Conference on the Origin and Development of Language and Speech, v. 280, p. 20-32, 1976.

GABORA, L.; ROSCH, E.; AERTS, D. Toward an Ecological Theory of Concepts. Ecological Psychology, v. 20, n. 1, p. 84-116, 2008.

GLASER, B. G.; STRAUSS, A. L. The discovery of grounded theory: strategies for qualitative research. London: Aldine Transaction, 1967.

HAMPE, B. Image schemas in Cognitive Linguistics: introduction. In: HAMPE, B. (Ed.), From perception to meaning: image schemas in Cognitive Linguistics. Berlin: Mouton de Gruyter. 2005, p. 1-14.

LAKOFF, G. Don't think of an Elephant. Chelsea Green Publishing, Vermont, 2004;

LAKOFF, G. The Political Mind: why you can't understand 21st-century American politics with an 18th-century brain. New York: Viking, 2008.

MOLINA, M. COVIBOOK. Disponível em: https://www.mindheart.co/descargables. Acesso em: 13 ago. 2020.

NANCE, R. E. The time and state relationships in simulation modeling. Comm. ACM, v. 24, p. 173-179, 1981.

PARNAIBA, C. dos S.; GOBBI, M. C. Charge jornalística: definição, histórico e funções. Disponível em: http://congreso.pucp.edu.pe/alaic2014/wpcontent/uploads/2013/09/vGT17-Cristiane-Parnaiba-Maria-Cristina-Gobbi.pdf. Acesso em: 20 ago. 2020.

ROMUALDO, E. C. Charge jornalística: intertextualidade e polifonia. Maringá: Editora da Universidade Estadual do Maringá, 2000.

SANTANA, N. M. O. Estudo sócio-histórico-cognitivo das conceptualizações e categorizações do amor em cartas dos séculos XIX e XX. 2019. 215 f. Tese. (Doutorado em Língua e Cultura) Instituto de Letras, Universidade Federal da Bahia, Salvador.

SOUZA, L.; DRIGO, M. O. A charge política jornalística como processo sígnico. Verso e Reverso, São Leopoldo, v. 20, n. 43, 2006.

THIRY-CHERQUES, H. R. Saturação em pesquisa qualitativa: estimativa empírica de dimensionamento. Revista Brasileira de Pesquisas em Marketing (PMKT), v. 9, n. 1, p. 20-27, 2009.

Nota do editor:

Artigo submetido para avaliação em: 12 de setembro de 2020.

Aprovado em sistema duplo cego em: 07 de fevereiro de 2021. 